\section{$161 \quad$ RESVERATROL REDUCES VESSEL-GRAFT NEOINTIMAL FORMATION BY INDUCING ENDOTHELIAL DIFFERENTIATION OF RESIDENT PROGENITOR CELLS THROUGH A MIR-21/AKT/B-CATENIN PATHWAY}

P Campagnolo, X Hong, Y Hu, 0 Xu KCL

doi:10.1136/heartjnl-2013-304019.161

Background Vessel graft failure is typically associated neointimal formation and arteriosclerosis, in which endothelial dysfunction/ damage is a key event.1 Resveratrol has been shown to possess cardioprotective capacity and to reduce atherosclerosis, through its anti-oxidant and anti-apoptotic properties.2-4 However, it is unknown whether it influences the behavior of resident stem cells in the vessel wall leading to the development of arteriosclerosis.

Methods and results In the present study, the mouse model of vein grafts was established by grafting vena cava to carotid artery using a cuff technique. ApoE knockout animals were randomly assigned to two groups, one receiving a diet enriched with resveratrol and one control group on a normal diet. It was found that neointimal lesions 4 weeks postoperatively were significantly reduced in resveratrol-treated group compared to untreated controls. Immunostaining for cell components in the grafts revealed the presence of Sca-1+ progenitor cells in the lesional adventitia and neointima of vein grafts. Subsequently, Sca-1+ cells from 4-week vein grafts were cultivated and isolated. Interestingly, stem/progenitor cell differentiation into endothelial lineage was markedly increased by treatment with resveratrol in vitro. We investigated the mechanism involved in the resveratrol-induced progenitor cell differentiation and identified miR-21 as a target of resveratrol. We demonstrated that resveratrol significantly reduced miR-21 expression during endothelial differentiation of progenitor cells, which in turn reduced Akt phosphorylation. This signal cascade diminished the amount of nuclear $\beta$-catenin, ultimately inducing endothelial marker expression and tube-like formation capacity in stem/progenitor cells. Both the inhibition of miR-21 and the knockdown of $\beta$-catenin were able to resemble the effect of resveratrol application, i.e. reducing endothelial differentiation. Finally, the effect of resveratrol on progenitor cell differentiation was blunted by the overexpression of miR-21.

Conclusion We provide the first evidence that oral administration of resveratrol can reduce neointimal formation in an animal model of vein graft, by inducing re-endothelialization through progenitor cell differentiation. We established that the mechanism involved is miR-21/Akt/ $\beta$-catenin dependent. These findings might contribute to explain the beneficial effect of red wine consumption on vascular disease.

\section{REFERENCES}

1 Nakazawa G, Finn AV, Joner M, et al. Delayed arterial healing and increased late stent thrombosis at culprit sites after drug-eluting stent placement for acute myocardial infarction patients: An autopsy study. Circulation 2008;118:1138-1145.

2 Breen DM, Dolinsky VW, Zhang $\mathrm{H}$, et al. Resveratrol inhibits neointimal formation after arterial injury through an endothelial nitric oxide synthase-dependent mechanism. Atherosclerosis 2012;222:375-381.

3 Zhang L, Zhou G, Song W, et al. Pterostilbene protects vascular endothelial cells against oxidized low-density lipoprotein-induced apoptosis in vitro and in vivo. Apoptosis 2012;17:25-36.

4 Delucchi F, Berni R, Frati C, et al. Resveratrol treatment reduces cardiac progenitor cell dysfunction and prevents morpho-functional ventricular remodeling in type-1 diabetic rats. PLOS ONE 2012;7:e39836. 